\title{
Action Research as a Bottom-up Approach to Foster Teacher Involvement in Language Curriculum Change
}

\author{
Mina Saghaieh Bolghari \\ Department of English Language, College of Foreign Languages and Literature, Science and Research Branch, Islamic \\ Azad University, Tehran, Iran \\ Arezoo Hajimaghsoodi \\ Department of English Language, College of Foreign Languages and Literature, Science and Research Branch, Islamic \\ Azad University, Tehran, Iran
}

\begin{abstract}
Despite the popularity of action research in the field of teacher education and professional development, not much is found regarding the role of action research in language curriculum development. This lack of interest may stem from the dominance of top-down approach over curriculum development in some EFL contexts where no special place is given to the local needs and wants. This paper starts with the definition and some basic characteristics of action research and then follows with a brief overview of its origins as well as different types. How action research can make changes in a curriculum is discussed next. Then it looks at the role action research may play in creating positive changes in teachers' roles in curriculum development. Some of the challenges of implementing action research are mentioned later. Finally, the paper ends with some guidelines for teachers to make improvements as a result of conducting action research.
\end{abstract}

Index Terms-action research, bottom-up curriculum, curriculum development, top-down curriculum

\section{INTRODUCTION}

Action research (hereafter referred to as AR) is not a new concept applicable to only second language education. Rather, it is a well-known practice in several fields. As the word indicates, AR has a simultaneous focus on action and research and it is often problem-oriented and interventionist (Burns, 2005b; Van Lier, 2004). The purpose of AR, according to Mckernan (1987, p. 7), is to help practitioners understand and hopefully solve curriculum problems. The literature is replete with numerous definitions of AR, among which a definition offered by Carr and Kemmis's (1986) is frequently cited. They define AR as "it is simply a form of self-reflective enquiry undertaken by participants in order to improve the rationality and justice of their own practices, their understanding of these practices and the situations in which the practices are carried out" (p. 162). To Mckernan (1987), multiple definitions of AR may not be useful to solve curriculum problems, but they can offer perspectives on the curriculum problems to be resolved. The main concern of AR, according to Elliot (1991), is unifying teaching, curriculum development, evaluation, educational research, and professional development.

In second language teaching/learning studies, AR emerged as a means of professional development paralleled with evolving interest in learner-centered curriculum and classroom-based research (Burns, 2009). According to Van Lier (1994, p. 31), "AR is a type of research through which the practitioners are assumed the best people to carry out research on their own practices, sometimes with the help of outsiders and academics who have some relevant expertise to offer". Kemmis and Mctaggart (1988, as cited in Nunan, 1992) point out that AR mainly has three major characteristics: It is carried out by practitioners, it is collaborative, and it is aimed at changing things. Moreover, according to Burns (2005a), the central characteristics of AR are the enhancement of practice, the development of new theoretical understandings, and the introduction of change into the social enterprise.

Besides, AR as a valid approach that involves teachers in research gives eminence to the role of the teacher in curriculum development. This view is particularly significant in fields such as language teaching. The range of teacher involvement in curriculum development is determined by how the term curriculum is defined. According to Ornstein and Hunkins (2004), the curriculum was seen as a plan for action during the early 1900s. Along these lines of characterizing, the curriculum was also called the content-centered, objectives or traditional approach (p.9). In this approach, teacher involvement in curriculum development was centered to a great extent on implementing the content to obtain the product. Hence, teachers' involvement in the configuration or distribution and assessment stages was not stressed. However, with the development of learner-centered approach in the late 1960s and 1970s, the role of teachers and students and their cooperation in curriculum decisions has been greatly emphasized (Ramparsad, 2001). To Burns (2011), this change in teachers' role as curriculum negotiators results from AR. 
The purpose of this paper, accordingly, is to argue for a need to incorporate AR practices as a bottom-up approach to change and modify the curriculum and enhance teacher involvement in curriculum development.

\section{ORIGINS AND HISTORICAL DEVELOPMENTS OF AR}

In second language education, AR emerged only from the late 1980s (Burns, 2005b, 2009, 2011). However, its origin traces back to some decades ago.

As McKernan $(1987,1988,2008)$ mentions, AR firstly emerged in The Science in Education Movement in the early $19^{\text {th }}$, during which scholars such as Dewey (1910, as cited in McKernan, 1987) asserted that scientific methodology can be adopted in educational research to improve the curriculum in a collective way among the researchers and practitioners (Burns, 1999). However, curriculum development was not yet in the hands of practitioners in classrooms (McKernan, 1987). Teachers were viewed as researchers working scientifically in their classrooms although several progressive thinkers later labeled this image as 'a teacher as a scientist' (McKernan, 1988). According to Clark (1987) during this period, AR was influenced by progressive philosophy in which learners were becoming responsible for their own learning which was paralleled with a similar concern for teachers becoming responsible for improving their own teaching in the classrooms.

Later on, Kurt Lewin (1946, 1948, as cited in Burns, 1999), a social psychologist in the USA, discussed AR as a form of experimental research aimed at groups experiencing social problems. McKernan $(1987,1988,2008)$ calls this period as Group Dynamics Movements. Lewin, who has been generally regarded as "the father of action research" (McNiff, 1988, as cited in Burns, 2005a, p. 242), argued that social problems should be the main focus of social science research. He then proposed a mode of research composed of action cycles including analysis, fact-finding, planning and evaluation of action steps (Burns, 1999; McKernan, 1987, 1988). Like Dewey, Lewin emphasized the collaborative nature of AR.

While different variations of Lewin's model have been proposed over the decades, the best-known version is given by Kemmis and McTaggart (1988, as cited in Burns, 1999) as a four-stage process namely, planning, action, observation, and reflection. Teachers should first develop a plan of action to improve the situation. Then they act to implement the plan followed by observation of the effect of this action. Finally, they reflect on these effects for further planning.

However, inherent problems of this type of AR such as intergroup relations and prejudice led a shift of attention to classrooms and materials (Mckernan, 1987, 1988). Corey's (as cited in Burns, 2005a) work in AR in the United States was one of the first attempts to integrate the so-called scientific AR into education although his work was then criticized for its inability to be validated in terms of scientific method standards (Burns, 1999, 2005a). It was the time for the decline of AR in the United States, from which AR basic tenets were gradually permeated other countries (McTaggart, 1991, as cited in Burns, 1999).

According to Burns (1999), a renewed interest in AR was linked to the emergence of the curriculum as a field of educational research which became popular in the British educational context in the 1970s. McKernan (1987, 1988, 2008) calls this period as Teacher-as- Researcher Movement which was mainly followed by Stenhouse (1975, as cited in Burns, 1999, 2005a, 2005b, 2011) who saw AR as a key component in the testability of curriculum concepts. Stenhouse developed a vision of teachers who could benefit from case studies in their own classrooms as practical knowledge resources to inform educational policy and practice (Somekh \& Zeichner, 2009). Stenhouse' ideas were then extended by some of his colleagues such as Elliot (1991) who considered teaching as a moral and theoretical activity shaped by teachers' context-bound values. Recent attempts in teacher professionalism, in-service education, schoolbased curriculum development, and professional self-evaluation are rooted in the teacher as researcher movement (Burns, 1999; Mckernan, 1987, 1988, 2008).

\section{APPROACHES TO AR IN CURRICULUM}

AR can be implemented in different ways depending on its purpose. For the purpose of curriculum change or testability of curriculum concepts, it is believed that AR should be implemented in collaboration between local teachers and outsiders such as educational researchers, curriculum developers, policy makers, etc. However, there is a degree in such collaboration.

In a taxonomy of approaches to AR, Hendricks (as cited in Ary, Jacobs, Sorensen, \& Walker, 2014, p. 551) refers to four types of AR. While classroom AR involves teachers in their classrooms (it may involve groups of teachers as well), collaborative AR, critical AR, and participatory AR are mainly relied on collaboration. To Hendricks, collaborative AR involves multiple researchers such as school and university personnel or teachers and school administrators. Critical AR needs wide collaboration including university researchers, school administrators, teachers, and community members and participatory one involves collaboration among stakeholders in a social process. The purpose of the last two is largely yielded social change and even transformation in the case of participatory AR.

With another well-known classification, Carr and Kemmis (1996, p. 202) distinguish between three kinds of AR: Technical, practical, and critical-emancipatory although Zeichner (1993) believes this classification creates a hierarchy that devalues practitioners. Each type is briefly discussed below. 
To Burns (2005a, 2009), technical AR is the same Corey's (as cited in Burns, 2005a) scientific method through which teachers can seek improvements to their practice. According to Carr and Kemmis (1996), technical AR occurs when teachers are asked by outsiders to test the findings of external research in their own local classrooms where the main concern is the development and extension of research literature, not the practitioners' own reflective practices. Such studies, Carr and Kemmis believe, may lead to improvement in practices from the viewpoint of outsiders, and even from the perspectives of teachers themselves but they may only be authentic in outsiders' viewpoints. The relationship between insiders and outsiders, therefore, is limited and one-way imposed from the above and cooperation and collaboration are seldom emphasized in this kind.

In practical AR, "outside facilitators form cooperative relationships with practitioners, helping them to articulate their own concerns, plan strategic action for change, monitor the problems and effects of changes, and reflect on the value and consequences of the changes actually achieved" (Karr \& Kemis, 1986, p. 203). Therefore, the main concern in practical AR, according to Karr and Kemmis, is to develop the practical reasoning of teachers as individuals and perhaps that is why it is labeled as 'practical'. The practical is also connected to the process rather than the product of research (Mckernan, 1996, as cited in Burns, 2005a). By referring to Mckernan, Burns (2005a, 2005b, 2009) also connects practical AR to Stenhouse's and Elliot's (1991) works in the teacher as researcher movement.

Practical AR is also conceptualized, in narrow terms, as classroom AR. As one type of classroom research (Mackey, 2009), this kind of AR is mainly localized and unpublished (Burns, 2009). According to Kemmis and McTaggart (2005, pp. 273-274), "classroom AR typically involves the use of qualitative interpretive modes of inquiry and data collection by teachers for making judgments about how to improve their own teaching practices and hence enhance students' learning." In this line, there is no need to imposed, cooperative, or collaborative relations between teachers and facilitators.

The third approach to AR is Critical-emancipatory which has been introduced first by Carr and Kemmis in 1986. Carr and Kemmis were not satisfied with a problem-solving approach to AR. They asserted that there is an urgent need for a critical dimension to be added to AR which means going beyond the immediate practices of the individual classrooms to analyze critically how these practices are mediated by the unexamined assumptions of the educational system (Crookes, 1993).

Carr and Kemmis (pp. 203-204) argued that in contrast to practical AR that focused on individualistic judgments, the form of AR which best embodies the values of a critical AR is emancipatory. They believe emancipatory AR paves the way for testing and improving educational practices. At the level of teaching and learning, it provides a method by which teachers and students can explore and improve their own classroom practices. At the level of the curriculum, it provides a method for exploring and improving the practices which constitute the curriculum. Thus, as Carr and Kemmis stress, emancipatory AR includes forms of practical AR but extends it into a collaborative context.

Crookes (1993) argues that critical-emancipatory AR has gone without any representation in the field of second language teaching, where the individual type has been much more emphasized to empower professional development. Somekh and Zeichner (2009) believe that Carr and Kemmis have described a vision for the future rather than a current reality, and more recently they themselves (Carr \& Kemmis, 2005, as cited in Somekh \& Zeichner, 2009) admit that some key aspects of their perspectives toward AR have not been realized.

\section{AR AND CURRICUlum CHANGE}

Reviewing different approaches to $\mathrm{AR}$, one probably reaches a conclusion that $\mathrm{AR}$ is conducted either collaboratively or individually. While the former focuses on curriculum change or improvement usually with cooperation and collaboration among all participants, the latter just focuses on teachers' local practices, reflections, and learning improvements mainly by the individual teachers and practitioners not necessarily aided from the outside. The collaboration in this case, therefore, is shared between the classroom teacher and students and possibly other teachers and students.

One point which is argued in this article is that AR is not performed in a vacuum. So, AR can't likely be classified as collaborative and individual, since every type of AR is done in a social classroom context, within a community composed of at least a teacher and some students and so individualized AR in micro level seems meaningless in this sense. Collaboration in local classroom AR could be defined between the teacher and the students as actual participants and even between teachers as a community to share their experiences and provide with each other guidance and assistance. Depending on the purpose of AR, hence, the kind and level of collaboration can be varied.

As the literature indicates, the fundamental importance of collaboration is strongly accentuated in AR. According to Burns (1999), the major goal of AR is to bring about changes in social situations as a result of group problem solving and collaboration. Even Kemmis and McTaggart (1988, as cited in Burns, 1999) believe that the approach is only AR when it is collaborative. More importantly, Burns (1999) argues that collaborative AR is more empowering than individualized type since it offers a strong framework for whole-curriculum change. Policies and practices are open to change when these changes are brought up through collaborative pressures since the results are more reliable and valid than those of individual ARs (Burns, 1999).

Despite the significant place of collaborative AR in the curriculum, it is rare in current activities in the ELT field (Burns, 2009, 2011). One noticeable example, however, is Mathew's (1997, as cited in Mathew, 2006) study which 
described a large-scale curriculum implementation project in India aimed to evaluate the different aspects of a new English curriculum with a communicative framework in secondary schools. The Project involved teachers as researchers in understanding the curriculum-as-reality. To this end, teachers were trained to do AR to assess the feasibility of a communicative curriculum in their own local schools. The impacts of this longitudinal AR (1993-1997) have been summarized by Mathew (2006) as follows: a) effective instruction including better student-student interaction, more opportunities for skills practice, and more efficient evaluation procedures, b) an awareness of CLT principles, c) a feeling of satisfaction and confidence, d) better self-concept, e) becoming self-observant and more critical, and f) seeing oneself as a change agent.

However, according to Kemmis and McTaggart (2005, p. 277), not all theorists of AR place this emphasis on collaboration. Rather, theses theorists argue that AR is frequently a solitary process of systematic self-reflection. Nunan (1992), also, does not believe that collaboration should be seen as a defining characteristic of AR. He asserts that many teachers who are interested in exploring the process of teaching and learning in their own classrooms are unable or reluctant to do collaborative research. The work that such people carry out should not be disregarded as AR.

Nunan also argues that AR should not necessarily be concerned with change. He believes a descriptive case study of a particular classroom, group of learners, or even a single learner is an AR if it is initiated by a question, is supported by data and interpretation and is carried out by a teacher investigating aspects of his or her own context. It is probably arguable that classroom AR is unwillingly adhered to the curriculum change since the whole process of curriculum development is so prolonged and sophisticated that some minor changes in individual classrooms have no special room to form major changes.

Nunan (1994), elsewhere, truly discusses that AR may not work all the time. He refers to the results of his three case studies of action research in different ESL and EFL contexts. Each of these projects suffered from serious problems. According to Nunan, the effectiveness of AR largely depends on the context in which it exists.

According to Zeichner (1993), also, separations between technical and critical AR and/or micro and macro AR are distortions. He argues the critical AR is in reality embedded in the technical and in the micro-level of the local teachers and this means that every classroom has a critical dimension. Zeichner holds that while we cannot ignore efforts to change or restructure the curriculum pillars, the classroom is an important context for critical AR connected to the struggle for greater educational equity and social justice. Like Nunan (1992), Zeichner believes that teachers may not be able to change unjust societal structures through their classroom AR, but they can make important changes in terms of affecting the life chances of their students. He believes that there is no need for teachers to necessarily move out of their classrooms to connect AR with the struggle for educational reform and social justice. To Zeichner, these efforts should be encouraged and supported, but not at the expense of classroom AR and the dignity of teachers.

\section{AR AND TEACHER INVOVEMENT IN CURRICULUM DEVELOPMENT}

$\mathrm{AR}$ is a progressive approach which offers bottom-up curriculum renewal where there is a shift from the ready-made top-down curriculum to support a local bottom-up one involving teachers in their own development programs (Clark,1987). According to Ramparsad (2001), many schools, for the most part, used to purchase a canned curriculum and afterward utilize conventional staff training/development to train teachers how to use the curriculum. To Wong (2009), however, a new curriculum needs to be adapted to or modified by the realities of the local classroom which therefore needs to undergo a process of mediation in which bottom-up participation of teachers and students comes into play. According to Carless (1999, as cited in Wong, 2009) in bottom-up curriculum development usually a general direction is outlined from above, but classroom implementation is controlled by the teachers. Similarly, McKernan (2008) refers to school-based curriculum development that has emerged as a result of the failure of large expert-led national curriculum projects in England. This conception of curriculum planning derives from the needs and wants of learners. It further suggests that schools should be responsive to their own environment. In addressing this environment, it is vital that teachers be researchers and curriculum developers in adapting learning to its own local contexts (McKernan, 2008).

AR with its self-reflective nature changes the traditional role of the teacher in the curriculum from a technician within the classroom to a "decision-maker, consultant, curriculum developer, analyst, activist, and school leader" (Cochran-Smith \& Lytle, 1999, p. 17). Therefore, AR by confirming teachers as experts inside the classroom setting permits new space for teachers to investigate (Price \& Valli, 2005). Teachers can participate in decision making and curriculum theorizing. They get to be mindful and responsive to both theory and practice (Manfra, 2009; Sarac-Suzer, 2007). In other words, AR puts the teachers in the dual role of producer and user of educational theory (Riding, Fowell, \& Levy, 1995). It means that teachers are not only followers of new methodologies but also the source and maker of the theoretical premise of their own implementation techniques, getting to be researchers inside the regions of their own classroom. It additionally supplies teachers with ownership in deciding both the content and procedure of their own curriculum (Ramparsad, 2001).Hence, without considering its type, AR can change teachers roles from passive practitioners, who are probably imposed from the top-down model, to be active agents in bottoum-up curriculum development.

Changing the nature of teacher involvement in curriculum, AR leads self-directed teachers to promote their own professional self-development (Nunan, 1990, p.64). It can also enable teachers to be changed by pushing a teacher out 
of his/her comfortable state and thus stimulating personal and professional development. The difficulties teachers faced when being pushed out of a comfort zone are essential, especially in classroom practice to prompt positive change. According to Mertler (2006), AR puts the teacher in numerous new roles such as researcher, decision maker, and change agent. Performing AR process has helped notify daily instruction and it has changed and extended teachers' curriculum points of view, decisions, and thinking.

Furthermore, according to Nunan (1990), reflection is one of the key characteristics of self-directed teachers who condunct AR. Carr and Kemmis (1986) additionally expound on the advantages of reflection in AR claiming "while practical experience can be gained through unsystematic reflection on action, a rational understanding of practice can only be gained through systematic reflection on the action by the actor involved. The knowledge developed by action researchers about their own practices is of this kind" (p.189).

Taking part in AR can also affect teachers' every day and future instructional practices. Based on Ferrance (2000) and Sax and Fisher's (2001) studies, AR gives teachers more trust in their own work. According to them, teachers by carrying our AR seemed to be more in control of and sure about every day and future pedagogical practices and choices. According to Parsons and Brown (2002), AR prompts enhancements in educational practice. In addition, AR process makes teachers more aware of their teaching practices and more discerning of their students' needs. In particular, educators can particularly examine how the AR process affirms, confirms, or extends specific instructional practices and curriculum programs. AR process as stated by teachers can also make them more conscious of new procedures and strategies and give them the confidence to try them. Besides, according to Manfra (2009), AR formalizes teachers' investigation and enables them to influence their insider knowledge to change classroom practice. He believes AR changes the customary outside-in relationship between teachers and educational community.

Finally, changing and developing the nature of classrooms as a result of doing AR may lead to curriculum change (Brown, 2012). Field (1998, p.49, as cited in Brown, 2012) refers to two important reasons for classroom AR which might be beneficial to curriculum change, especially in the ELT field. The first reason proposed by Field is that despite universal similarities between classrooms, each one is unique in reality because of various factors such as student background, motivation, nationalities, personalities, and different levels. Therefore, AR is required to be matched to the unique circumstances of each particular classroom that leads to curriculum change. The second reason as Field mentions is what he calls the compelling argument. It means that AR releases teachers from the restricts and confines of tradition. He asserts, "We need to recognize that much of what passes as good practice in ELT has no scientific evidence to back it up. It is simply the result of an amalgam of experience, myth, and wishful thinking" (p.49). Moreover, considering that theories of language teaching are changing frequently and none of them are even scientifically confirmed, AR is used to help teachers discover what works and what does not in a particular situation.

\section{Challenges of ImPlementing AR in CURRICUlum DeVelopment}

In spite of the various benefits of $A R$, there are seemingly various difficulties experienced in performing it. One of the most important difficulties recognized by Burns $(1995$, p.11) in his project was "teachers having the time to carry out research in addition to their usual teaching" and the related problem of "the logistics of documenting or collecting data during busy classroom time." Each teacher can refer to the problem of lack of time in his or her teaching and claims that performing research can just add to this. Time is an important obstruction for AR as well as the entire matter of curriculum development. As a result, many teachers, due to lack of time, prefer to use the ready-made top-down curriculum despite the attractiveness and usefulness of participating in AR and curriculum development projects. Therefore, Nunan (1989) suggests that "If language teachers are to be charged with the responsibility of developing their own curricula, they need more time and greater skills and more support than if they are implementing a curriculum developed by others" (p. 3).

Carr and Kemmis (1986, p.152-153) notice another possible challenge of AR including the traditional "separation of educational research from educational practice " causing an inclination for individuals not to normally create AR groups. They propose that mediation is important to make the acknowledgment of a requirement for AR despite the fact that this has its own particular problems in increasing the individual mediation to that of "someone with superior knowledge" which overcomes the principle of "participatory, collaborative forms of critical self-reflection" which are indispensable parts of AR.

Another significant argument has been the capacity of teachers to take the responsibility of research because it is claimed that they are instructed to teach and not to research (Burns, 2011). A further point of view on this discussion has been in admiration of the irrational requests that AR puts on teachers. Offering the question "Is AR a 'natural' activity for teachers?", Allwright (2005) asserts that AR compels teachers to accept "research aptitudes taken from the scholastic collection" (p. 355).

McKernan (1993) led an overview of constraints on AR amongst 40 projects conducted in educational settings in the USA, UK, and Ireland. The most frequent constraints were lack of time, resources, research skills, and school organizational features. Besides, obtaining consent/support to research, language of research, pressure of student examination, and disapproval of principal were considered as constraints. Regarding human factors, McKernan further found disapproval of colleagues, beliefs about the role of the teacher, professional factors (union policies, contract), and student disapproval as causes of restrictions. 
Although such a broad study has not been conducted in the field of second language teaching, different scholars have proposed that these sorts of limitations are comparatively a reality for most TESOL teachers (e.g. Allwright, 1993; Brindley, 1991; Burton \& Mickan, 1993; Nunan, 1993; van Lier, 1994, as cited in Burns, 1999).

\section{CONCLUDING REMARKS}

One of the most prominent areas of educational research, according to McKernan (2008), is the curriculum because knowledge is communicated through this medium. How the curriculum is planned, implemented, and evaluated depends on many factors, among which policy has a potential role (McKernan, 2008). While according to Nunan (1989), it is difficult for a top-down or centralized curriculum system to work in the field of ELT curriculum development, many EFL contexts, such as Iran (the researchers' native country), still rely heavily on this type. AR is a potential way to make a possible shift from top-down to a local bottom-up approach in curriculum development. Curriculum change starts with the developing and changing the nature of classrooms and teacher invovement (Brown 2012), since, according to Somekh and Zeichner (2009) AR is grounded in the values and culture of its participant-researchers and hence, it is flexible to the local agency.

Moreover, according to Brown (2012), the advantages of AR in the field of language teaching and curriculum development overwhelmingly surpass the problems in spite of the fact that the issues of time, training, and interest must be taken into consideration before the development of AR in a particular educational setting. AR, previously utilized in various educational settings, is a significant device to advance curriculum change particularly in fields such as language teaching and situations where the teacher endures a great amount of responsibility for curriculum development. In addition, AR encourages professional self-development and is appropriate for teachers' own particular class situations. It manages actual issues that teachers are encountering and gives them not only a practical mechanism to enhance their own teaching practices but also a step towards curriculum change at all institutional levels. To sum up, AR is an effective approach that influences on daily and/or future teaching and elicits changes in curriculum development.

However, although teacher involvement is crucial to the achievement of a curriculum, teachers alone cannot develop and support it. Curriculum results could be better accomplished when the curriculum is contextualized to the requirements of its beneficiaries. As a result, the voices of all curriculum stakeholders should be included to obtain intended curriculum outcomes (Wiles \& Bondi, 2007).

At last but not least, some recommendations for teachers are mentioned to improve the curriculum with the help of AR:

- Teachers should start with themselves. The change of teacher's attitude to see teachers as change agents is crucial. Teachers as action researchers should undergo a personal change in their theory of teaching, including their views of the nature of the teaching and assessment processes, and of themselves as teachers, such as strengths, weaknesses, areas needing improvement, and so on. (Li, Yu, Lam \& Fok, 1999)

- Collaborative AR should be emphasized as well. As Burns (2009) argue, this kind of AR is rarely preferred in EFL settings. Teachers should share their knowledge and experiences collaboratively to solve their own problems. Some scholars such as Wells and Wells (1992, as Cited in Burns, 2009) offer a notion of communities of inquiry where opportunities are set up for teachers and researchers to construct knowledge about AR collectively over time. Pedagogical knowledge construction thus occurs through dialectic interaction and critical exchange.

- As Crookes (1993) mentions, teachers should put an emphasis on critical AR to facing up to the unquestioned values embodied in educational contexts.

- And finally, Successful change agents are the result of self-realization and initiation supported by appropriate staff development programs as well as initial and in-service training programs ( $\mathrm{Li}$, et al., 1999).

All these may not be achieved if we don't admit a lack of interest in doing AR in our own intended context. If the lack of AR is properly understood, relevant support can be given to practitioners to carry out AR and curriculum improvements (Li, et al., 1999).

\section{REFERENCES}

[1] Allwright, D. (2005). Developing principles for practitioner research: The case for exploratory practice. The Modern Language Journal, 89(3), 353-366. doi:10.1111/j.1540-4781.2005.00310.x.

[2] Ary, D., Jacobs, L. C., Sorensen, C., \& Walker, D. A. (2014). Introduction to research in education (9th ed.). Belmont, CA: Wadsworth Cengage Learning.

[3] Brown, I. (2012). Action research and curriculum change. Studies in Languages and Cultures, 28, 185-192. Retrieved from http://catalog.lib.kyushu-u.ac.jp/handle/2324/21807/p185.pdf (accessed16/12/2015).

[4] Burns, A. (1995). Teacher researchers: Perspectives on teacher action research and curriculum renewal. In A. Burns \& S. Hood (Eds.), Teachers' Voices: Exploring course design in a changing curriculum (pp.3-20). Sydney: NCELTR.

[5] Burns, A. (1999). Collaborative action research for English language teachers. Cambridge: CUP.

[6] Burns, A. (2005a). Action research. In E. Hinkel (Ed.), Handbook of research in second language teaching and learning (pp. 241-256). Mahwah, NJ: Lawrence Erlbaum Associates.

[7] Burns, A. (2005b). Action research: An evolving paradigm? Language Teaching, 38(2), 57-74. doi:10.1017/S0261444805002661. 
[8] Burns, A. (2009). Action research in second language teacher education. In A. Burns \& J. C. Richards (Eds.), The Cambridge guide to second language teacher education (pp. 289-297). Cambridge: CUP.

[9] Burns, A. (2011). Action research in the field of second language teaching and learning. In E. Hinkel (Ed.), Handbook of research in second language teaching and learning (Vol. II, pp. 237-253). New York, NY: Routledge.

[10] Carr, W., \& Kemmis, S. (1986). Becoming critical: Education, knowledge and action research. London: Falmer.

[11] Clark, J. (1987). Curriculum renewal in school foreign language learning. Oxford: OUP.

[12] Cochran-Smith, M., \& Lytle, S. L. (1999). The teacher research movement: A decade later. Educational Researcher, 28 (7), 1525. doi:10.3102/0013189X028007015.

[13] Crookes, G. (1993). Action research for second language teachers: Going beyond teacher research. Applied Linguistics, 14(2), 130-144. doi: 10.1093/applin/14.2.130.

[14] Elliott, J. (1991). Action research for educational change. Milton Keynes: Open University Press.

[15] Ferrance, E. (2000). Themes in education: Action research. Providence, RI: The Education Alliance.

[16] Kemmis, S., \& McTaggart, R. (2005). Communicative action and the public sphere. The Sage handbook of qualitative research, 3, 559-603.

[17] Li, W. S., Yu, W. M., Lam, T. S., \& Fok, P. K. (1999). The lack of action research: the case for Hong Kong. Educational Action Research, 7(1), 33-50. doi: 10.1080/09650799900200079.

[18] Manfra, M. M. (2009). Action research: Exploring the theoretical divide between practical and critical approaches. Journal of Curriculum and Instruction (JoCI), 3(1), 32-46. doi: 10.3776/joci.2009.v3n1p32-46.

[19] Markee, N. (1997). Managing curricular innovation. Cambridge: CUP.

[20] Mathew, R. (2006). Tracing the after-life of teacher development programs: reopening closed chapters. English Language Teacher Education and Development, 9, 21-37.

[21] McKay, S. L. (2009). Second language classroom research. In A. Burns \& J. C. Richards (Eds.), The Cambridge guide to second language teacher education (pp. 281-288). Cambridge: CUP.

[22] McKernan, J. (1987). Action research and curriculum development. Peabody Journal of Education, 64(2), 6-19. Retrieved from http://www.jstor.org/stable/1492700 (accessed 22/5/2016).

[23] McKernan, J. (1988). The countenance of curriculum action research: Traditional, collaborative, and emancipatory-critical conceptions. Journal of Curriculum and Supervision, 3(3), 173-200.

[24] McKernan, J. (1993). Varieties of curriculum action research: constraints andtypologies in American, British and Irish projects. Journal of Curriculum Studies, 25(5), 445-457. doi:10.1080/0022027930250504.

[25] McKernan, J. (2008). Curriculum and imagination: Process theory, pedagogy and action research. London: Taylor \& Francis.

[26] Mertler, C. A. (2006). Action research: Teachers as researchers in the classroom. Thousand Oaks, CA: Sage.

[27] Nunan, D. (1989). Understanding language classrooms: A guide for teacher- initiated action. New York: Prentice Hall.

[28] Nunan, D. (1990). Action research in the language classroom. In J. C. Richards \& D. Nunan (Eds.), Second Language Teacher Education (pp.62-76). Cambridge: CUP.

[29] Nunan, D. (1992). Research methods in language learning. Cambridge: CUP.

[30] Nunan, D. (1994). The more things change, the more they stay the same: Or why action research does not work. In R. Berry, V. Berry, \& D. Nunan (Eds.), Bringing about change in language education (pp. 1-20). Hong Kong: Department of Curriculum Studies.

[31] Ornstein, A. C., \& Hunkins, F. P. (2004). Curriculum: Foundations, principles, and issues. Boston, Mass: Allyn and Bacon.

[32] Parsons, R. D., \& Brown, K. S. (2002). Teacher as reflective practitioner and action researcher. Belmont, CA: Wadsworth /Thomson Learning.

[33] Price, J. N., \& Valli, L. (2005). Preservice teachers becoming agents of change: Pedagogical implications for action research. Journal of Teacher Education, 56 (1), 57-72. doi: 10.1177/0022487104272097.

[34] Ramparsad, R. (2001). A strategy for teacher involvement in curriculum development. South African Journal of Education, 21(4), 287-292. Retrieved from http://www.ajol.info/index.php/saje/article/view/24917/20529 (accessed 16/7/2016).

[35] Riding, P., Fowell, S., \& Levy, P. (1995). An action research approach to curriculum development. Information Research: An International Electronic Journal, 1(1). Retrieved from http://www.informationr.net/ir/1-1/paper2.html (accessed 2/11/2015).

[36] Sarac-Suzer, H. S. (2007). Action research. Retrieved from http://www3.telus.net/linguisticsissues/actionresearch (accessed 24/6/2016).

[37] Sax, C., \& Fisher, D. (2001). Using qualitative action research to effect change: Implications for professional education.

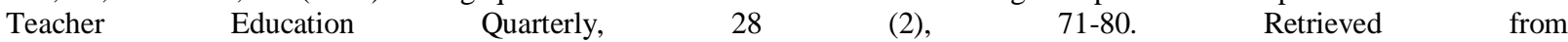
http://www.teqjournal.org/Back\%20Issues/Volume\%2028/VOL28\%20DS/28_2/v28nsax\&fisher.pdf (accessed 11/3/2016).

[38] Somekh, B. (2006). Action research: A methodology for change and development. Maidenhead: Open University Press.

[39] Somekh, B., \& Zeichner, K. (2009). Action research for educational reform: Remodelling action research theories and practices in local contexts. Educational Action Research, 17(1), 5-21. doi: 10.1080/09650790802667402.

[40] Van Lier, L. (1994). Action research. Sintagma, 6, 31-37. Retrieved from www.raco.cat/ (accessed 13/12/2015).

[41] Van Lier, L. (2004). The ecology and semiotics of language learning a sociocultural perspective. Boston: Kluwer Academic Publishers.

[42] Wiles, J., \& Bondi, J. (2007). Curriculum development: A guide to practice (7th ed.). NJ: Pearson Prentice Hall.

[43] Wong, M. (2009). Perspectives on the English language education of Hong Kong's New Senior Secondary (NSS) curriculum. Professional Teaching Articles, 35, 1-27.

[44] Zeichner, K. (1993). Action research: Personal renewal and social reconstruction. Educational Action Research, 1(2), $199-219$. doi: 10.1080/0965079930010202. 
Mina Saghaieh Bolghari is currently a Ph.D. candidate of TEFL at Tehran Islamic Azad University, Science and Research Branch. Her main areas of research interest include Activity Theory, classroom-based assessment, and cooperative learning.

Arezoo Hajimaghsoodi is currently a Ph.D. candidate of TEFL at Tehran Islamic Azad University, Science and Research Branch. Her main areas of interest include Activity Theory, CALL, and Discourse Analysis. 